ISSN 1112-9867

\title{
COMPARISON OF WORKING MEMORY, DIVIDED AND SELECTIVE ATTENTION IN CHILDREN WITH DIFFERENT TYPES OF ATTENTION DEFICIT HYPERACTIVITY DISORDER- ADHD
}

\author{
J. Nezhadianbaran ${ }^{1 *}$, R. Jafari ${ }^{2}$, M. Mohammadi ${ }^{3}$ \\ ${ }^{1}$ Baran Clinic, Iran \\ ${ }^{2}$ Garjani Clinic, Iran \\ ${ }^{3}$ Tarannomzafar Clinic, Iran
}

Published online: 15 February 2017

\begin{abstract}
Introduction: Attention Deficit and Hyperactivity are among the most common behavioral disorders in children which include three subgroups including inattention, hyperactivity impulsivity (disinhibition) and mixed form. Attention Deficit and Hyperactivity Disorder might be along with basic symptoms in memory and attention and Working memory and various forms of selective and divided attention are compared in this study in hyperactive children and children with attention deficit.
\end{abstract}

Method: in this study, 40 hyperactive children and children with attention deficit who have referred to children's psychiatric and occupational therapy centers in Tehran in 2016 have been selected as sample using stratified random sampling. This was a descriptive-analytic study. Data were collected using Kim Karad's working memory test and Stroop's selective and divided attention test. Obtained data were analyzed using SPSS software.

Findings: findings showed significant difference between average working memory of three groups of children with attention deficit, hyperactivity and mixed form.

Author Correspondence, e-mail: author@gmail.com

doi: http://dx.doi.org/10.4314/jfas.v9i1s.733 
In this way that working memory in mixed form group had the weakest average, attention deficit had moderate average and hyperactive had the highest average. Comparison of selective and divided attention also indicated a significant difference between groups. In this way that, selective attention of children with mixed form with the least of all and it was the highest of all in hyperactive children. Divided attention or attention management was also the weakest in mixed form group and it had a higher average than the rest in hyperactive type.

Discussion and conclusion: based on objectives and method of the research which was comparative, findings showed that active visual memory was more damaged in children with mixed form compare to two types of hyperactive children or children attention deficit. Also, findings related to comparison of selective and divided attention showed that selective and divided attention was lower in hyperactive children with mixed attention deficit compared to hyperactive children and was lower than attention deficit type in the next level.

Keywords: selective attention, divided attention, hyperactive, attention deficit, mixed

\section{INTRODUCTION}

One of the most common disorders in children is attention deficit hyperactivity disorder (ADHD) (Diagnostic and Statistical Manual of Psychological Disorders, 2013)). This disorder has three sub-groups: 1) Inattention2) hyperactivity - impulsivity (disinhibition) 3) mixedform. This means some are with Inattention and some are just impulse while some of these children have both at the same time. The main problem of ADHD children is their inability to maintain and adjust their behavior. Hence, they cannot show an appropriate behavior whichmatches the environmental conditions of each moment. Attention deficit disorder in these children is more evident in tasks which require permanent and serious brainactivities. They might not be different from other children in watching television, playing computer and enjoyable activities but their difference with other children is revealed in activities which require constant activity of brain and focus(such as homework). It seems like their brain takes environmental datamore than necessary limit which means there is a defect in selection of essential information and ignorance andremoving unnecessary information. Compliance with rules at home or school is difficult for them and they need more attention to follow the rules. They face problems in doing homework, focusing on education,Compliance with rules at work and having good social relationships with peers. They do not plan to achieve long-term goals (Casper, 2006). Existence of 6 to 9 symptoms 
ofhyperactivity-attention deficit disorder symptoms and clear impaired functioning at least in two locations (usually home and school) are required for the diagnosis of ADHD according to DSMV(Diagnostic and Statistical Manual of Psychological Disorders, 2013). Early onset of hyperactivity-attention deficit shows that hyperactivity-attention deficit might have substantial symptoms in memory and attention due to neurocognitive disorders ((Heidari, 2012).

Memory has several types and each have their own functions(Xing et al., 2016). In general, all of these divisions are based on two perspectives which are processing levels perspective and structural perspective. Based on processing levels perspective, data is recorded in memory with two types of superficial and deepencoding which leads to formation of two different types ofshort-term and long-term memories (Picard et al., 2013). A famous classification of memory was presented by Broadbent (1985; quoted by Lewis and Frank, 2016) after this classification which is still the most general classification. Broadbent's classification divides memory to three sensory, short-term and long term systems and information passes from one memory to another in hierarchy form. Short-term memory is also called working or active memory (Poussin et al., 2016).

Attention is a type of mental-physical efforton environmental stimuli which is done for better and faster understanding of those and more compliance with the conditions. Attention contains all information which is accessible from memory, perception and other cognitive processes and there is the possibility for its manipulation. One of the important functions of attention is detection of objects, shapes and important events for the individual in the environment. Therefore, attention is divided into two types of selective (optional) and divided(fragmented).

Selectiveattention is that an individual selects which stimulus he/she must pay attention to and which stimulus he/she mustignore. Ignoring or emphasizing certain stimuli will particularly focus on leading or focused stimuli. Focused attention on some informational stimuli will increase the ability of other cognitive processes such as verbal understanding or solving strengthen to manipulate those (Khodadadi, Yazdi and Amani, 2014).

Divided attention is that Individual is often able to simultaneously deal with more than one duty and be able to cautiously transferresources from one to other in proportion. For example, a student can focus on reading a textbook or paying attention to a lecture and ignore stimuli such as radio, TV or surrendering individuals which enter hall with delay (Khodadadi, Yazdi and Amani, 2014). 
Given that we cannot process all the information, we should select information which matter most to us which are known as selective attention or attention control(Zare, Moradi, Ghazi, Safari and Lotfi, 2014). Attention control refers to the ability to consciously suppress and shut down automated and dominant responses to provide more appropriate and targetedresponses(Rostami, Pourbakht, Kamali and Jalai, 2011).Stroop and the anti-saccade tests are among tests which are used to measure attention and there are needs for intentional and deliberate inhabitation and prohibition of relatively automaticresponse and it is also called divided attention (Best, Williams and Kokaro, 2012). However, the type of response which must be inhibitedis different between them. For example, in Stroop test, person is asked to only tell the color of words and that person must inhibitautomatic tendency to read the word itself (Miyake et al., 2010).Stroop and antisaccade tests are sensitive in relation to lesions of the frontal lobe and other and its other problems (Bidrano and Youn Day, 2007). According to Schulz et al (2007), the ability to resist the dominant response (response inhibition), provides great flexibility, freedom of choice and control. Deficits in controlling attention leads to malfunction and possible increased incorrect responses. It is thought that selective control of response might be a prerequisite for higher levels of skills for executive functions such as self-regulation, and self-control and purposeful behavior. Response inhibition, delays motion activity in this way that allows the individual to use multiple administrative processes.Definition of overall burden of response inhibition consists of three processes which work with each other. First process is inhibition of consolidated responses. Second process is stopping the current responses for delay and having opportunity to decide in order to provide response. Third process, is a role that is responsible for response inhibition in controlling interference. When a person uses interference control, delay inresponse keeps him/her from distraction associated with responding to competingevents and as a result, autonomy responses are allowed to be present (Best, Williams and Kokaro, 2012).

Researches have shown that symptoms of inattention are strongly associated with neurocognitive dimensions such as general cognitive abilities, short-term memory and working memory, processing speed, alertness and response diversity. In addition, many multiple regression analysis indicated that in case of controlled inattention, the relation between hyperactivity-impulsivity type and these neurocognitive results was not significant.In contrast,special neurocognitiveweaknesses have been identified for hyperactivity-impulsivity type. However, 
recent studies have reported promising results for some aspects of reward-related processing (For example, Lee and Sumiya, 2008).

Based on contradictions mentioned aboutdifference between functioning of hyperactivity types, the objective of this study is to determine whether there is a difference between visual Active Memory of children with different types of hyperactivity disorder with attention deficit or not. Also whether there is a relation between selective and divided attention of children with different types of hyperactivity or not. Hence, the objective of the present study is comparing the difference between Active Memory,selective and divided attention in children with attention deficit disorder,hyperactivity type and mixed form.

\section{RESEARCH METHOD}

This is a descriptive-analytic research. The study population included all children referred to child psychiatry clinics in Tehran in 2016 which have had diagnosis of attention deficit with hyperactivity. Stratified random sampling method was used for sample selection. In this way that we divided study population in terms of gender of children and disorder type to three hyperactive, with attention deficit and in mixed type groups and we randomly selected 10 samples from each group and at the end, 10 hyperactive children, 10 children with ADHD, and 10 children with mixed type were selected. Data were selected and used using Kim karad visual memory and Stroop shapes test(Ridley Stroop, 1995). Kim karad visual memory test consists of a cardboard Page with 20 spots and each spot has a colored imageand it also has a cardboard with 20 white spots with 20 pieces of cardboard and there are images of test page on each of them. This test can evaluate shortmedium and long -term visual memory. The reliability of this test is in acceptable range (Marnat, 2005).

Stroop test is also one of the most important tests which is used for measurement of selective and divided attention (Khodadadi et al., 2014).

After sample selection, the objective of research was initially explained for them and then Stroop test was carried out using a laptop. Data were collectedindividually in Tehran Psychiatric clinics. Data analysis wasperformedusing SPSS software.One way variance analysis and descriptive statistics were used to analyze the data. 


\section{FINDINGS}

Average Active Memory with selective and divided attention in three groups of children with attention deficithyperactivity and mixed type is in form of Table 1.

Table 1. shows average and the standard deviation of research variables in three groups

\begin{tabular}{|c|c|c|c|c|c|}
\hline Groups & variables & group & average & SD & Bias Error \\
\hline \multirow{4}{*}{ active memory } & $\begin{array}{l}\text { attention } \\
\text { deficit }\end{array}$ & 15 & 10.6000 & 1.68184 & .43425 \\
\hline & hyperactive & 15 & 10.9333 & 2.08624 & .53866 \\
\hline & mixed & 15 & 8.6667 & 1.98806 & .51331 \\
\hline & total & 45 & 10.0667 & 2.13627 & .31846 \\
\hline \multirow{4}{*}{$\begin{array}{l}\text { Selective } \\
\text { Attention }\end{array}$} & $\begin{array}{l}\text { attention } \\
\text { deficit }\end{array}$ & 15 & 105.9333 & 15.17266 & 3.91756 \\
\hline & hyperactive & 15 & 107.2000 & 20.85734 & 5.38534 \\
\hline & mixed & 15 & 88.2000 & 18.42436 & 4.75715 \\
\hline & total & 45 & 100.4444 & 19.91522 & 2.96879 \\
\hline \multirow{4}{*}{$\begin{array}{l}\text { Divided } \\
\text { attention }\end{array}$} & $\begin{array}{l}\text { attention } \\
\text { deficit }\end{array}$ & 15 & 147.4667 & 21.25648 & 5.48840 \\
\hline & hyperactive & 15 & 164.8667 & 11.23049 & 2.89970 \\
\hline & mixed & 15 & 144.6667 & 18.64582 & 4.81433 \\
\hline & total & 45 & 152.3333 & 19.39541 & 2.89130 \\
\hline
\end{tabular}

Table 2 shows results obtained from one way analysis of variance between three hyperactive, with attention deficit and mixed type groups. 
Table 2. results obtained from one way analysis of variance between three hyperactive, with attention deficit and mixed type groups

\begin{tabular}{|c|c|c|c|c|c|c|}
\hline \multicolumn{2}{|c|}{$\begin{array}{c}\text { variance source } \\
\text { dependent variables }\end{array}$} & \multirow{2}{*}{$\begin{array}{c}\begin{array}{c}\text { Sum of } \\
\text { squares }\end{array} \\
44.933\end{array}$} & \multirow{2}{*}{$\begin{array}{c}\text { SD } \\
2\end{array}$} & \multirow{2}{*}{$\begin{array}{c}\text { mean squares } \\
22.467\end{array}$} & \multirow{2}{*}{\begin{tabular}{c|}
$\mathbf{F}$ \\
6.054
\end{tabular}} & \multirow{2}{*}{$\begin{array}{c}\text { P- value } \\
.005\end{array}$} \\
\hline $\begin{array}{l}\text { active } \\
\text { memory }\end{array}$ & $\begin{array}{l}\text { Between } \\
\text { groups }\end{array}$ & & & & & \\
\hline & Intergroup & 155.867 & 42 & 3.711 & & \\
\hline & total & 200.800 & 44 & & & \\
\hline \multirow[t]{3}{*}{$\begin{array}{l}\text { Selective } \\
\text { Attention }\end{array}$} & $\begin{array}{l}\text { Between } \\
\text { groups }\end{array}$ & 3385.378 & 2 & 1692.689 & 5.054 & .011 \\
\hline & Intergroup & 14065.733 & 42 & 334.898 & & \\
\hline & total & 17451.111 & 44 & & & \\
\hline \multirow[t]{3}{*}{$\begin{array}{l}\text { Divided } \\
\text { attention }\end{array}$} & $\begin{array}{l}\text { Between } \\
\text { groups }\end{array}$ & 3593.200 & 2 & 1796.600 & 5.823 & .006 \\
\hline & Intergroup & 12958.800 & 42 & 308.543 & & \\
\hline & total & 16552.000 & 44 & & & \\
\hline
\end{tabular}

As it can be observed in table 2, the results show that there is a significant difference between average active memoryof three groups of children with attention-deficit, hyperactivity and mixed form (P-value $<0.005)$. There is also asignificant difference between selective attentions of children in these three group. In the end, there has also been a significant difference between three groups in terms of dividedattention( $\mathrm{P}$-value <.006).

Scheffe post hoc test was used to clarify which groupspair wisely differ from each other and its results are shown in table 3 .

Table 3. Pair wise comparison of dependent variables in three groups

\begin{tabular}{|c|c|c|c|c|c|}
\hline dependent variable & first group & $\begin{array}{l}\text { Group } \\
\text { criteria }\end{array}$ & $\begin{array}{c}\text { average } \\
\text { difference }\end{array}$ & $\begin{array}{c}\text { standard } \\
\text { deviation } \\
\text { Error }\end{array}$ & $\begin{array}{l}\text { Significa } \\
\text { ncy level }\end{array}$ \\
\hline $\mathrm{D}$ active memory & $\mathrm{ADD}$ & \begin{tabular}{|l|l|}
$d$ & $H D$ \\
\end{tabular} & -.33333 & .70343 & .894 \\
\hline
\end{tabular}




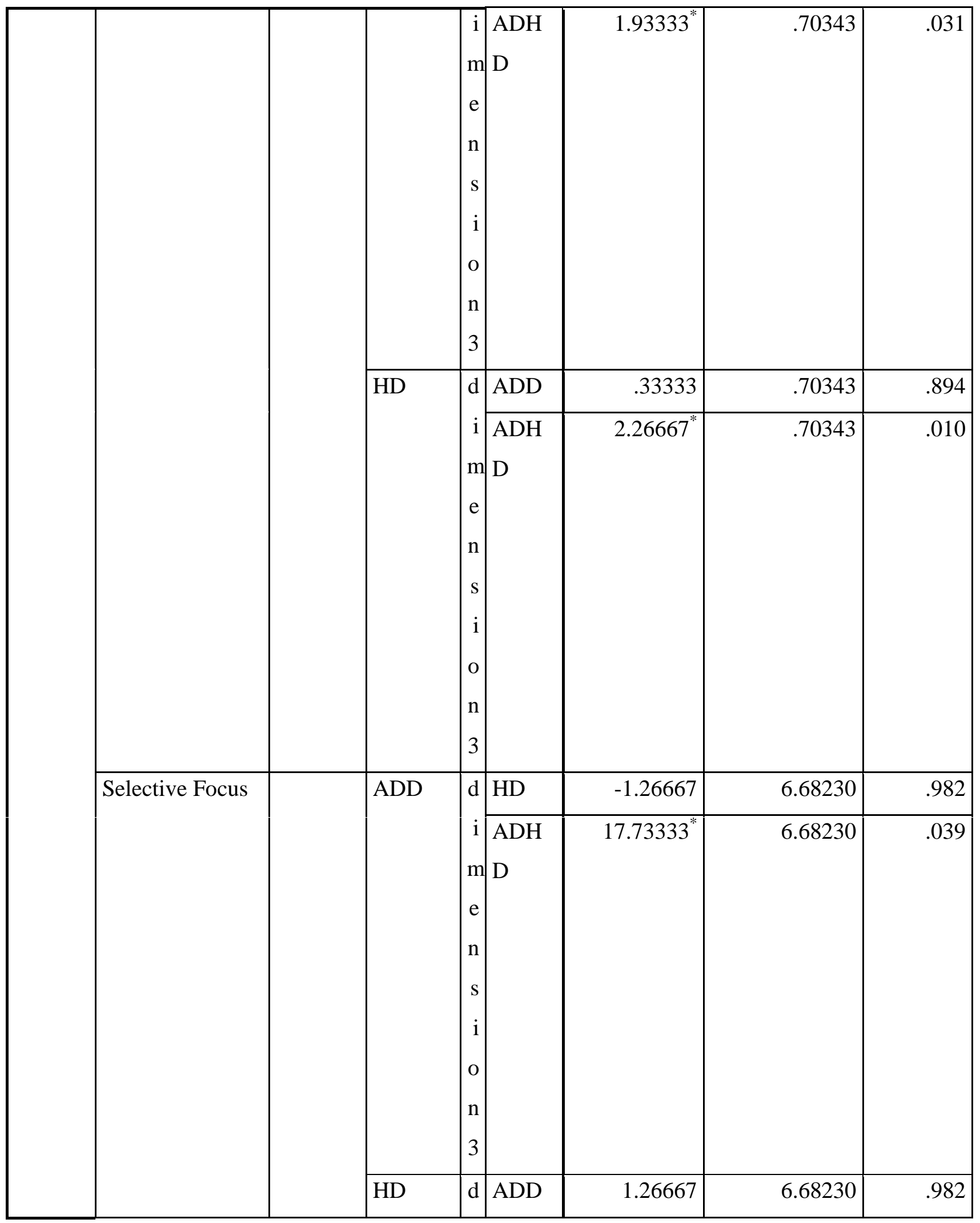




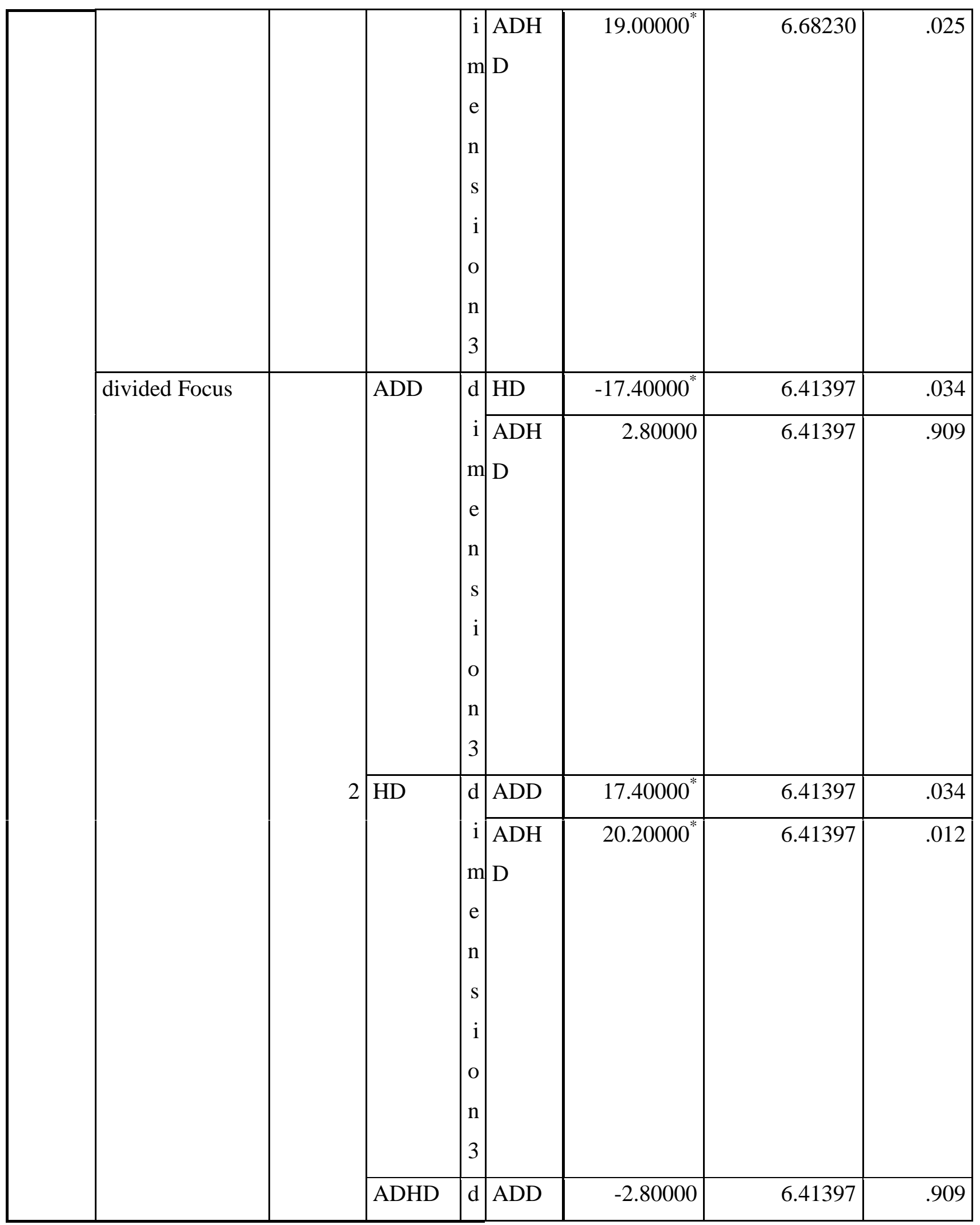




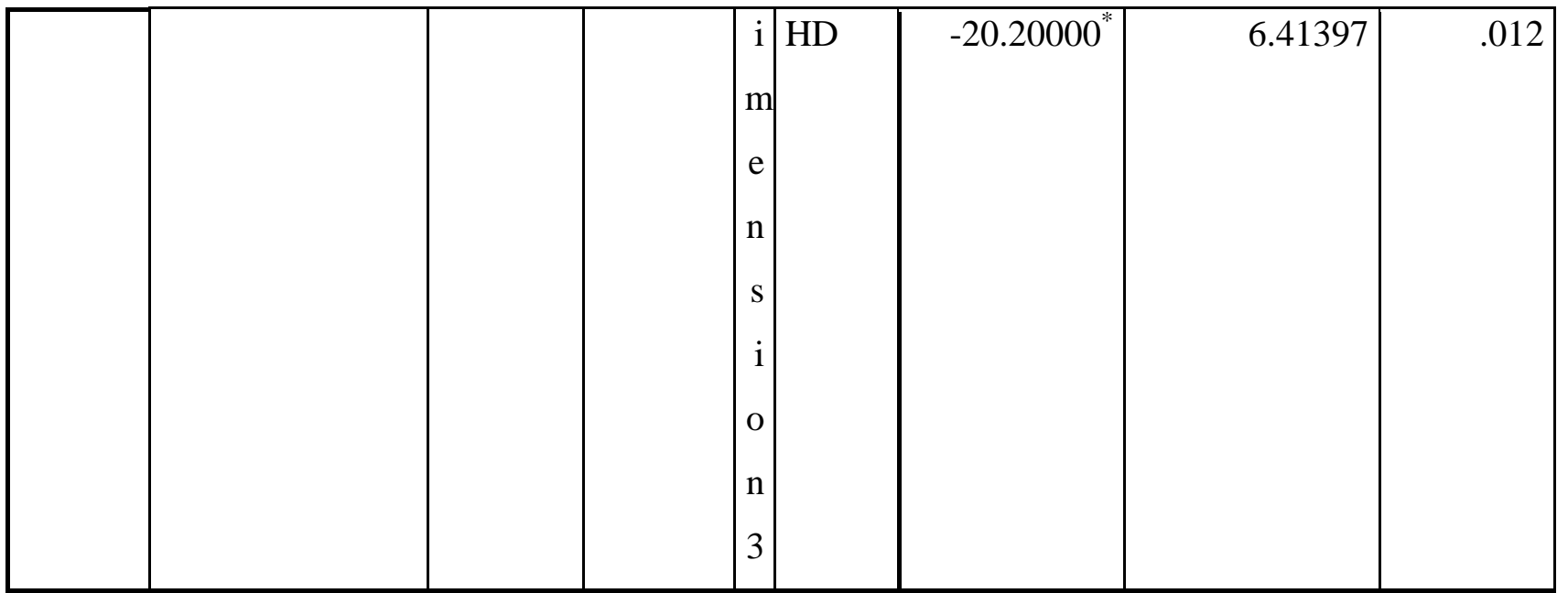

It can be said based on the results of above table that active memory of mixed group is damaged more than group with attention deficit and the memory of group with attention deficit is lower than hyperactive group. The results of selective and divided attention is in the same way. Hence, there was a significant difference between mixed group with two groups of with ADHD and deficient in all three measured variables.

\section{DISCUSSION}

The results of present research indicate significant difference betweenchildren with attention deficit, hyperactivity and mixed form in terms of all three variables of active memory, selective and divided attention. This finding is in line with results of other studies such as (Naig, 2010; Mashhadi et al., 2009; and Ghamari, 2014). For example, Mashhadi et al (2009) compared response inhibition and interference control in children withattention deficit hyperactivity disorder and normal children. The results showed that Performance of reaction time in congruent and incongruent stimuli in children with attention deficit hyperactivity disorder is significantly different compared to normal children. In case of interference control, the results of their study show that despite differencebetween children with ADHD and normal children. This difference is not statistically significant. Also, in case of Stroop testcomponents, despite difference between the performances of children with ADHD, this difference was not significant statistically. Performance of children with attention deficit was weaker than hyperactive children in terms of Stroop test. Naig (2010) distinguished different types ofinhibition including functional, motivational and inhibition processes in an extensive analysis. Executive inhibitory is defined as 
deliberatecontrol processes or response inhibition in higher level services with long-term goals which are evaluated by the paradigms such as Stroop. Changing sets contains mental flexibility andability to maintain and change subjective sets. Murashi and Anbel showed that performance of people up to the age of 15 years shows steady growth in inhibition tasks. In case of Stroop test, growth inhibition continues up to the age of 21 years. These results show gradual growth / maturation of cognitive inhibitionduring adolescence and even early adulthood(Luna et al., 2010). Also, Activity in the frontal region of the left side moves to the right side with increasing age and there are evidences for frontalization of cingulate activity with increased inhibition ability. Hence, growth and increase in inhibition in following years of childhood and adolescence might reflect focus (focus in center) and migration of nerve and brain activity toward frontal brain (Best, Williams and Kokaro, 2012).

Specific stimulation of left and right cerebral hemispheres is done via visual channel using HEMDTIM software. In visual stimulation, students are asked to look directly to one point in the middle of the screen and read words that appear on the right or left of this point. Words consecutively and temporarily appear in one of the visual fields (for a few seconds) and children should read these words out loud. Using this software, words individually appear in right visual field of students and temporarily appear in left visual field of students (Baker \& Robertson, 2002).

\section{CONCLUSION}

Previous researches have shown that Selective attention is different in children with attentiondeficit and hyperactivity and normal children. They are also different in reaction time in congruent and incongruentstimuli. In addition to this, performance of children with attention deficit was weaker compared to hyperactive children in terms of Stroop test but the results of present research showed that both Stroop tests which were selective and divided attention were lower in hyperactivegroup compared to group with attention deficit. This finding is not in line with previous studies which might be due to separation of mixed group from two hyperactive and attention deficit groups which has not be evaluated in previous studies. Another point is that the difference between the performances ofchildren with ADHD has not been statistically significant in Stroop test in previous studies while a significant difference was observed in this study between three groups of hyperactive children, children with attention deficit and mixed type in 
terms of selective and dividing attention and this is probably due to the weakness of previous studies to separate three groups from each other because children have been divided into three groups including with ADHD, attention deficit and mixed type based on Diagnostic Interview based on Fifth Edition of Detection of psychological disorders and this type of classification might have increased the resolution of these three groups. It can be said based on the present research and proposed explanations that damage to brain areas which control attentionand memory in people with attentiondeficit andhyperactive children and with mixed type is different which is better to be considered in future researches and interventions.

\section{REFERENCES}

Khodadadi, M;Yazdi, Side Manor and Amani, H. (2014).The application of selective and divided attention. Tehran: Cognitive Behavioral Sciences Research Institute of Sina.

Rostami, Soheila; Pourbakht, A.; Kamali, Mohammad and luster, (2011). The effect of auditory selective attention on inhibition of stimulus-frequency acoustic emission. Volume 20, Number 2 (36). 71-63.

Heidari, T, Amir, flame, Molavi, H. (2012). The effectiveness of methods of self-Davis Children with attention deficit with hyperactivity. Journal of Behavioral Sciences; 6 (2 (20)): 131-139. American Psychiatric Association. (2013). Diagnostic and Statistical Manual of Mental Disorder (5thed.). Washington, DC: American Psychiatric Association.

Aneett, M. (2001). Left, right, hand and brain: The right shift theory. Hillsdale, NJ: Erlbaum. Bryden, M. P. (1988). Cerebral specialization: clinical and experimental assessment. In: Boller, F., Grafma, J. editors. Handbook of neuropsychology. Amesterdam: www.Elsevier.com. pp.143159.

Cavill, S., \& Brayden, P. (2003). Development of handedness : Comparison of questionnaire and performance-based measures of preference. Brain and Cognition, 53: 149-151.

Chokron, S., \& De Agostini, M. (2000). Reading habits influence aesthetic preference. Cognitive Brain Research, 10: 45-49.

Clayton, I. C., Richards, J. C., \& Edwards, C. J. (1999). Selective attention in obsessivecompulsive disorder. Journalof Abnormal Psychology, 108(1), 171-175. 
Davies, D. R., Jones, D. M., \& Taylor, A. (1984). Selective and sustained-attention tasks: Individual and group differences. In R. Parasuraman, \& D. R. Davies (Eds.), Varieties of attention (pp. 395-447). Orlando, Fl: Academic Press.

Groth-Marnat, G., Howchar, H., \& Marsh, A. (2007). Memory performance in abstinent 3, 4methylenedioxymethamphetamine (MDMA, "ecstasy") users. Perceptual and motor skills, 104(1), $43-55$.

Kang, M. S., \& Oh, B. I. (2016). Grouping influences output interference in short-term memory: a mixture modeling study. Frontiers in psychology, 7.

Khodadadi, mojtaba.,yazdi, S. M., \& Amani, H. (2014). Selective and divided attention software. Institute for behavioral \& cognitive science. Tehran.

Kindt, M., \& Van Den Hout, M. (2001). Selective attention and anxiety: a perspective on developmental issues andthe causal status. Journal of Psychopathology and Behavioral Assessment, 23(3), 193-202.

Kirveskari, E., Salmelin,R., \&Hari, R. (2006). Neuromagnetic responses to vowels vs. tones reveal hemispheric lateralization. Clinical Neurophysiology, 117:643-647.

Kormi-Nouri, R., Nikdel, F., \&Arabzadeh, M. (2009). The effect of memory self-efficacy on episodicand semantic memory. Advances in Cognitive Science, 11(2), 19-26.

Lewis, M. L., \& Frank, M. C. (2016). Linguistic structure emerges through the interaction of memory constraints and communicative pressures.

Mathews, A., \& MacLeod, C. (1985). Selective processing of threat cues in anxiety states. Behaviour Research andTherapy, 23, 563-569.

Montgomery, J. W., Magimairaj, B. M., \& O’Malley, M. H. (2008). Role of working memory in typically developing children's complex sentence comprehension. Journal of psycholinguistic research, 37(5), 331-354.

Morgan A.B., Lilienfeld S.O. (2009).A meta-analytic review of the relation between antisocial behavior and neuropsychological measures of executive function, Clinical Psychology Review,1(20): 113-136.

Morrison, C. M., Ellis, A. W., \& Quinlan, P. T. (1992). Age of acquisition, not word frequency, affects object naming, not object recognition. Memory \& Cognition, 20(6), 705-714. 
Murty, V. P., FeldmanHall, O., Hunter, L. E., Phelps, E. A., \&Davachi, L. (2016). Episodic memories predict adaptive value-based decision-making.Journal of Experimental Psychology: General, 145(5), 548.

Nilsson, LG. (2010). Executive functions in individuals with intellectual disability . Research in Developmental Disabilities; 31: 1299-1304.

NOSRATI, K., \& KORMI, N. (2002). EPISODIC AND SEMANTIC MEMORIES AMONG QURAN RECITERS.

Novemsky, N., \& Ratner, R. K. (2003). The time course and impact of consumer's erroneous beliefs about hedonic contrast effects. Journal of Consumer Research, 29, 507-516.

Picard, L., Mayor-Dubois, C., Maeder, P., Kalenzaga, S., Abram, M., Duval, C., \&Piolino, P. (2013). Functional independence within the self-memory system: New insights from two cases of developmental amnesia. Cortex, 49(6), 1463-1481.

Pinel, J. (2001). Biopsychology. Boston: Allyn and Bakon.

Shallice, T., \& Burgess, P. W. (1991). Deficits in strategy application following frontal lobe damage in man. Brain, 114, 727-741.

Stadthagen-Gonzalez, H., Bowers, J. S., \& Damian, M. F. (2004). Age-of-acquisition effects in visual word recognition: Evidence from expert vocabularies. Cognition, 93(1), B11-B26.

Steinberg, D. D., (2013). An introduction to psycholinguistics. Routledge. Engel, U., \& Eckstein, R. (2002). Microforming - from basic research to its realization. Journal of Materials Processing Technology, 125, 35-44.

Tata, P. R., Leibowitz, J. A., Prunty, M. J., Cameron, M., \& Pickering, A. D. (1996). Attentional bias in obsessionalcompulsive disorder. Behaviour Research and Therapy, 34(1), 53-60.

Tulving, E. (2007). Are there 256 different kinds of memory? The foundations of remembering: Essays in honor of Henry L. Roediger, III, 1, 39-52.

Viggiano, M. P., Vannucci, M. (2001). Drawing and identify objects in relation to semantic category and handedness. Dipartimento di psicilogia Generale,93: 50-125.

Wagner, G., Kock, K., Reichenbach, J. R., Sauer, H., \& Schlosser, R. G. M. (2011). The special involvement of the rostrolateral prefrontal cortex in planning abilities: An event-related Wexler, D. B. (1981). The administration of psychiatric justice. In Mental Health Law (pp. 71113). Springer US. 
Wolf, M. Bowers, P. (2009). The question of naming speed deficits in developmental reading disabilities: An introduction to the double-deficit hypothesis. Journal of Learning Disabilities, 33, 322-334.

Zevin, J. D., \& Seidenberg, M. S. (2002). Age of acquisition effects in word reading and other tasks. Journal of Memory and language, 47(1), 1-29.

\section{How to cite this article:}

Nezhadianbaran J, Jafari R, Mohammadi M. Comparison of working memory, divided and selective attention in children with different types of attention deficit hyperactivity disorderadhd. J. Fundam. Appl. Sci., 2017, 9(1S), 853-867. 